\title{
QUALITY OF CARE
}

\section{IN DIABETIC PATIENTS}

M. Marcelino, A. Domingues, A. Pereira, D. Passos, F. Lopes, J. Raimundo, J. Silva, L. Lopes,

M. Brito, M. Lopes, M. Paradinha, P. Chambel, V. Santos, J. Jácome de Castro

Endocrinology Department

Armed Forces University Hospital, Lisbon

INTRODUCTION: Type 2 Diabetes Mellitus (T2DM) is a chronic disease, with prevalence increasing worldwide and its complications are major causes of early morbidity and mortality. Recent guidelines suggest the individualisation of glycaemic targets and glucose-lowering therapies.

The aim of this study was to determine the quality of care provided to type 2 diabetic patients in our institution, analysing metabolic control, cardiovascular risk factors and prevalence of diabetic complications.

METHODS: Transversal study with 423 type 2 diabetic patients, followed at our diabetes clinic.

RESULTS: A total of 423 patients were included in the study, with a mean age of $67 \pm 9,4$ years. $61,7 \%$ were men. Approximately $90 \%$ of patients were overweight $(41,9 \%$ obese $)$.

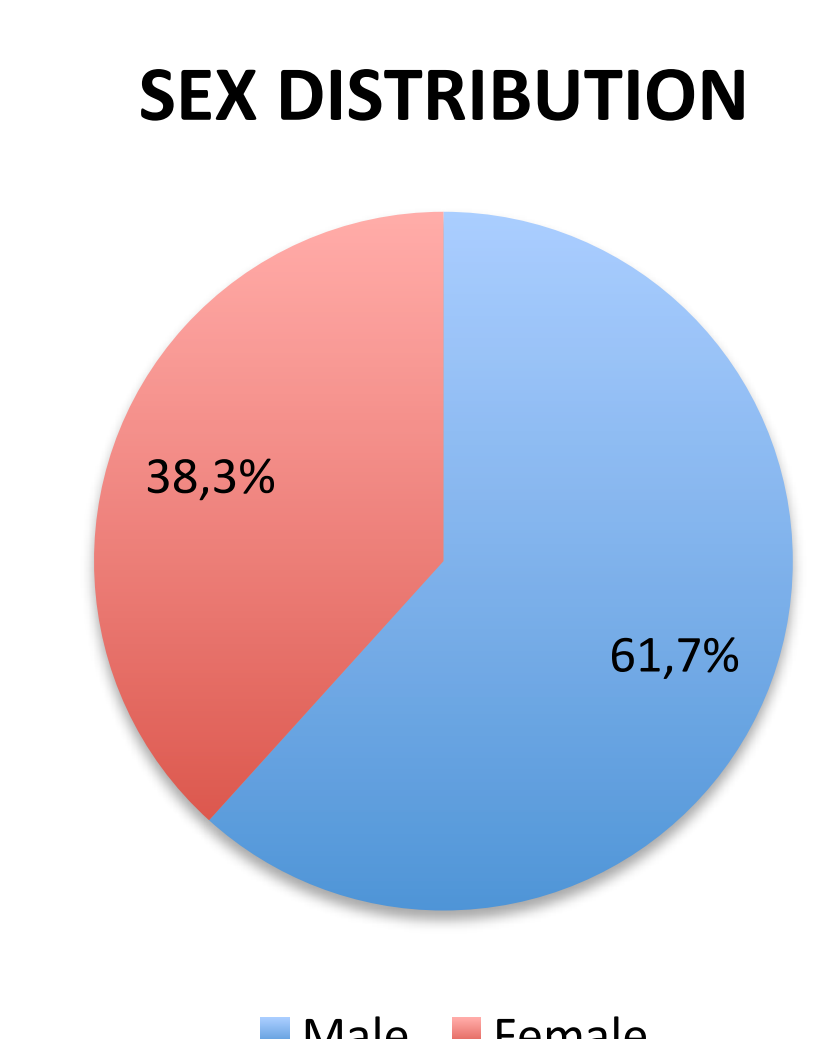

wale $=$ Female

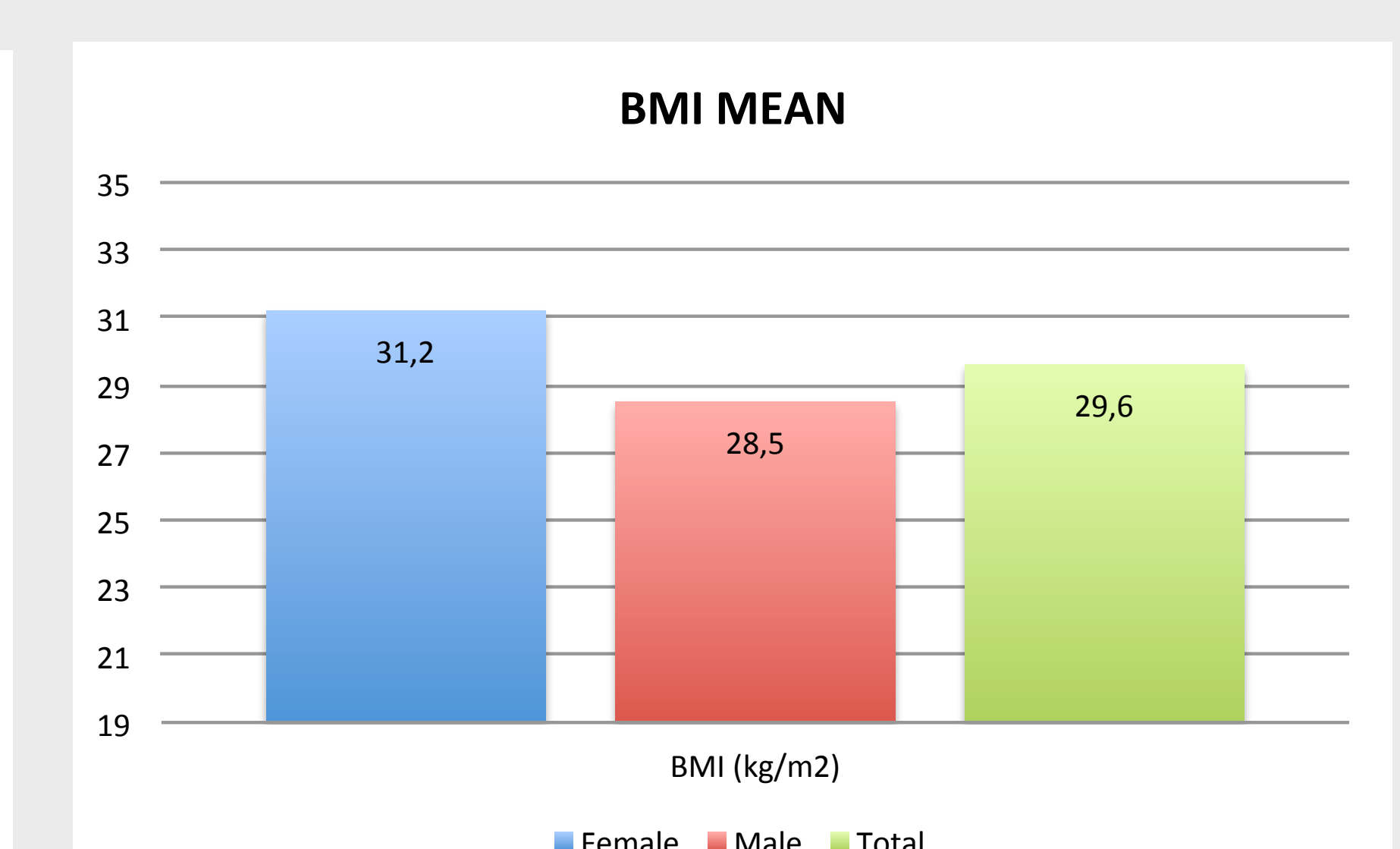

Female $=$ Male $=$ Total
$65,3 \%$ had familiar history of T2DM.

Mean duration of diabetes was $15 \pm 10,5$ years and $\mathrm{HbA} 1 \mathrm{c}$ levels averaged $7,0 \% \pm 1,2.60 \%$ had $\mathrm{HbA} 1 \mathrm{c} \leq 7 \%(40 \% \mathrm{HbA} 1 \mathrm{c} \leq 6,5 \%)$. Concerning therapeutic regimens: $75 \%$ used oral hypoglycaemic agents (OAD) alone (73,4\% of these were using 2 or more agents); $25 \%$ were treated with insulin (16\% in combination with OAD).

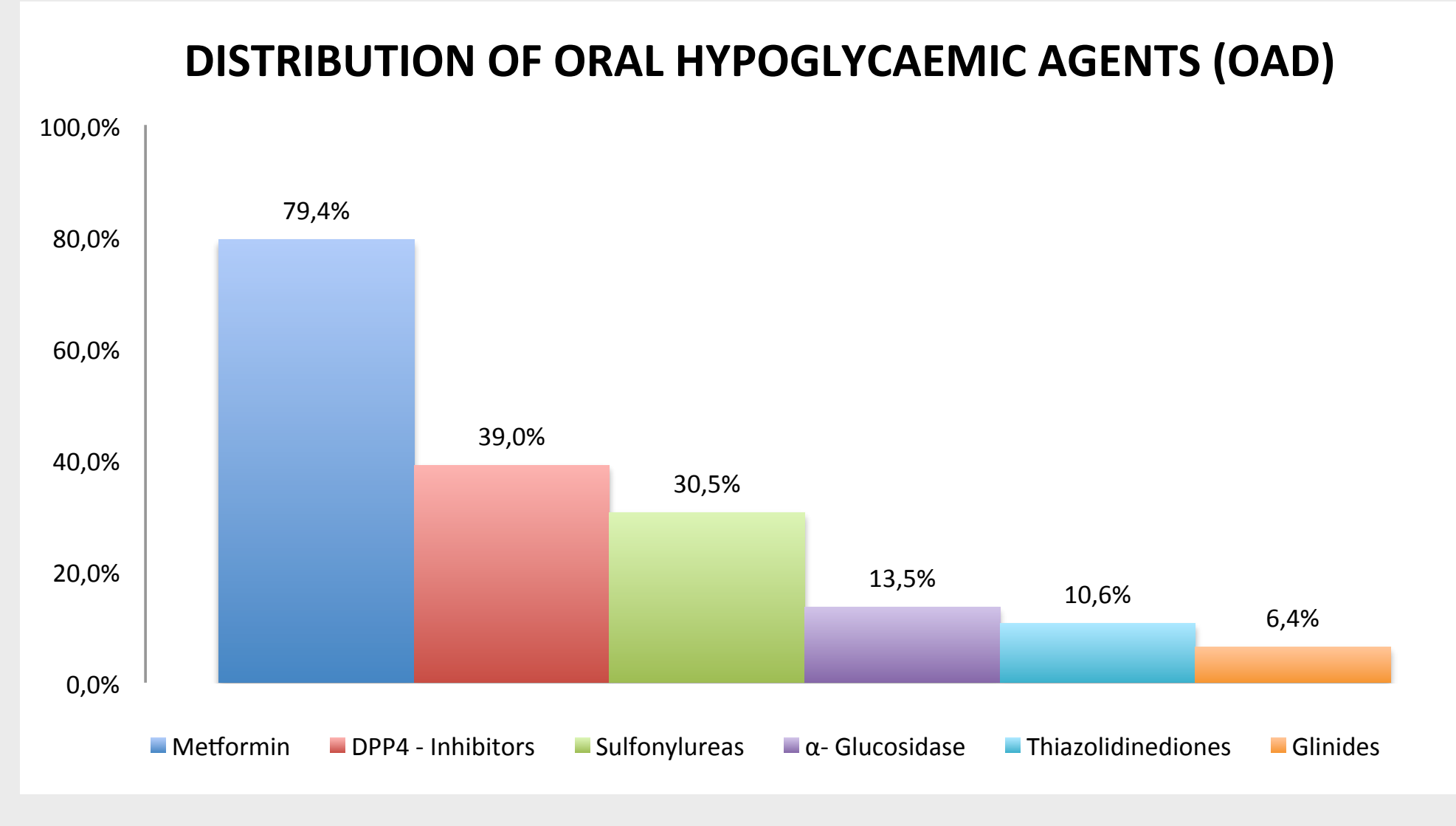

$82,3 \%$ of the patients had hypertension and $31,2 \%$ met the target blood pressure (BP) of 130/80mmHg. $82,9 \%$ had dyslipidaemia and $62,6 \%$ met the goal LDL cholesterol level $<100 \mathrm{mg} / \mathrm{dl}$. $12 \%$ of patients met the combined ADA goal for BP, LDL and $\mathrm{HbA} 1 \mathrm{c} .61,3 \%$ of the patients was anti-aggregated.

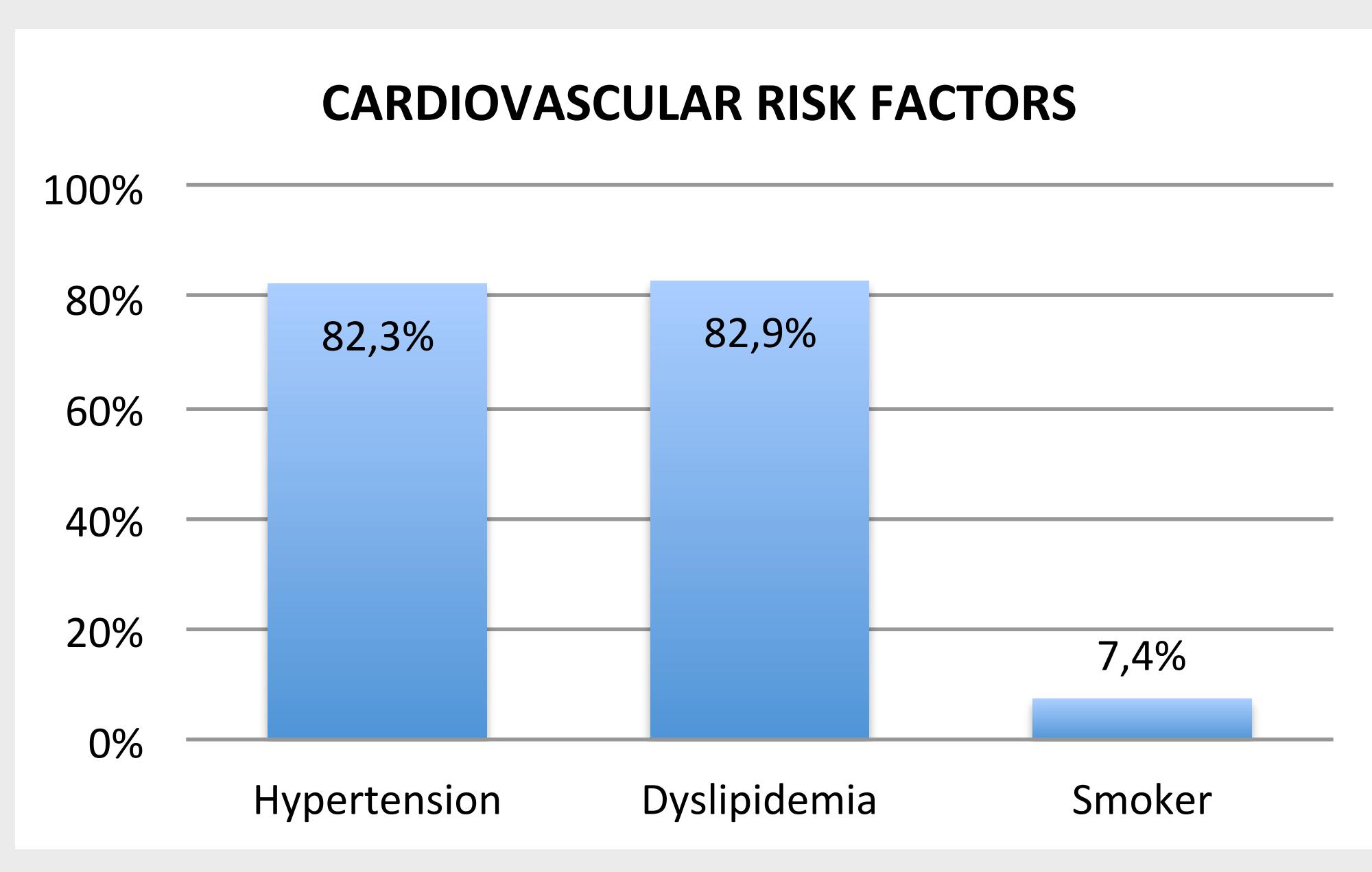

Regarding diabetic complications: $16,7 \%$ had retinopathy, $26,4 \%$ nephropathy, $23 \%$ cardiovascular and $8,7 \%$ cerebrovascular

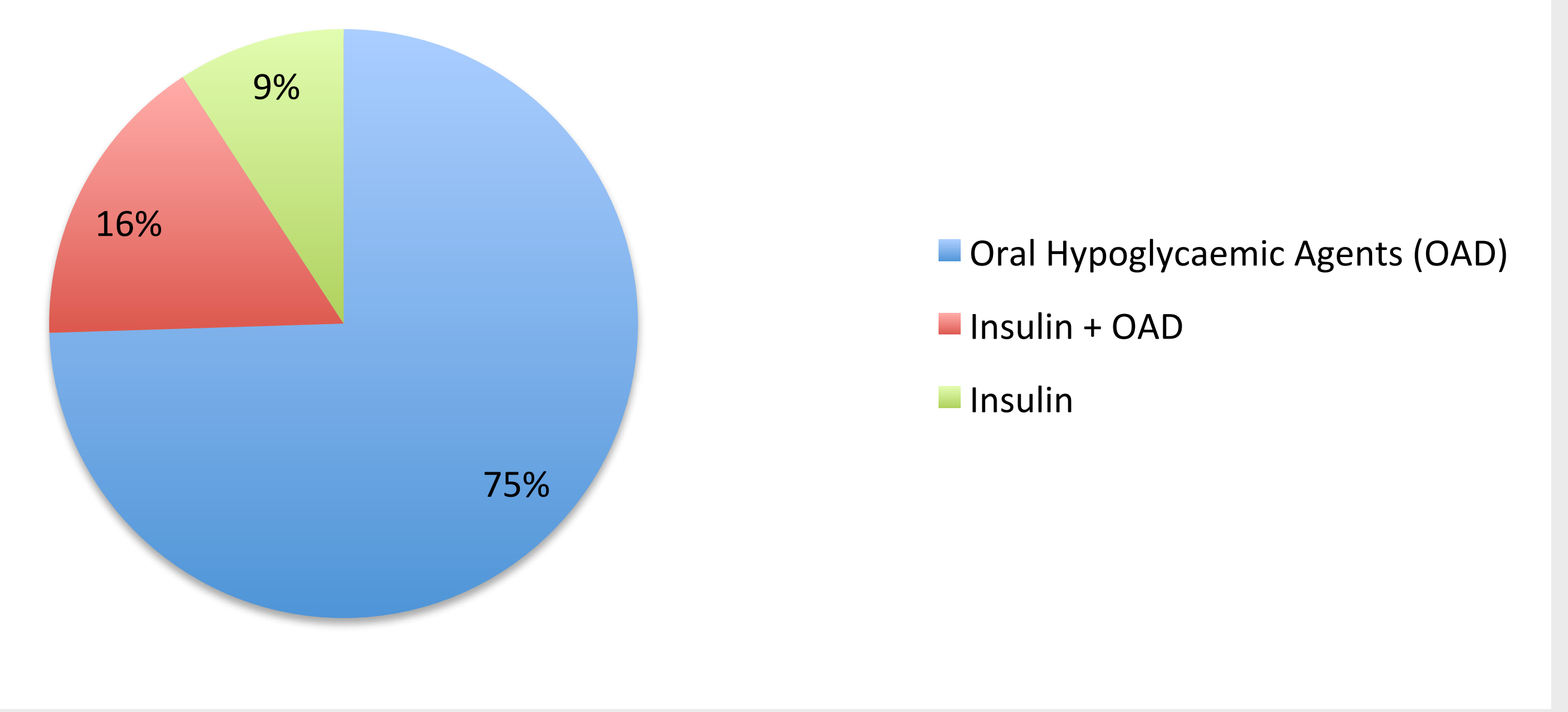
disease.

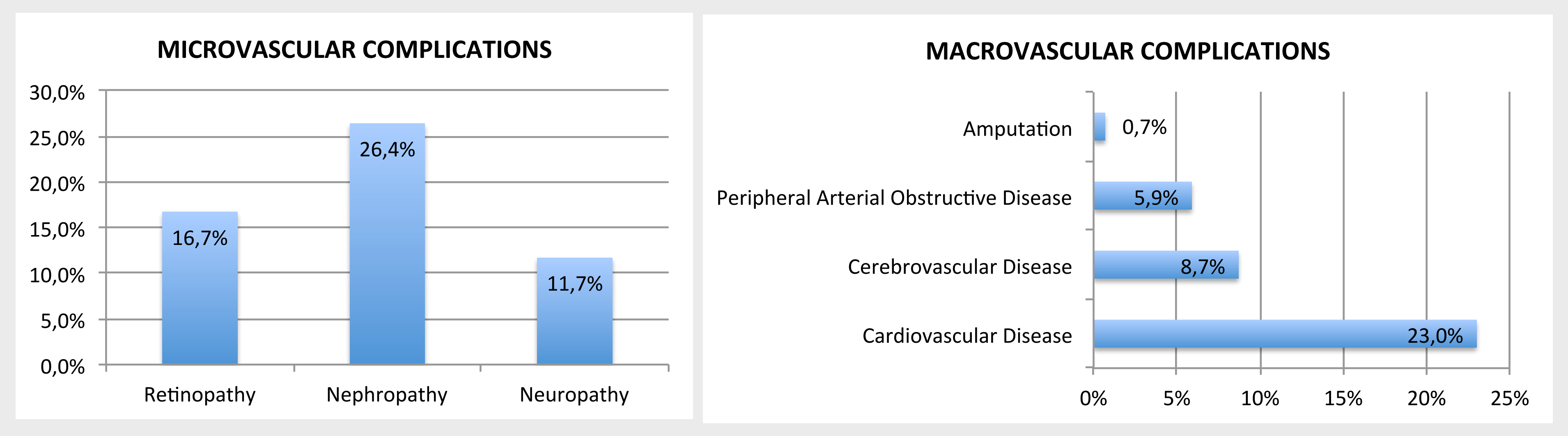

CONCLUSIONS: Metabolic control (HbA1c), BP, LDL values were favourable in our patients, comparing to other studies. Although, it's challenging to achieve all the goals proposed by international guidelines. 